Research Article

\title{
Differential survivorship of congeneric ornamental fishes under forecasted climate changes are related to anaerobic potential
}

\author{
Luciana Mara Fé Gonçalves ${ }^{1}$, Maria de Nazaré Paula da Silva ${ }^{1}$, Adalberto Luis Val ${ }^{1,2}$ and \\ Vera Maria Fonseca de Almeida-Val ${ }^{1,2}$ \\ ${ }^{1}$ Laboratório de Ecofisiologia e Evolução Molecular, Instituto Nacional de Pesquisas da Amazônia \\ (LEEM-INPA), Av. André Araújo, 2936; Petrópolis. 69067-375, Manaus, AM, Brazil. \\ ${ }^{2}$ Programa de Pós-Graduação em Aquicultura, Universidade Nilton Lins, Av. Professor Nilton Lins, 3259; \\ Parque das Laranjeiras 69058-030, Manaus, AM, Brazil.
}

\begin{abstract}
Two Amazonian closely related tetras - cardinal Paracheirodon axelrodi and green neon $P$. simulans - were artificially acclimatized to environmental chambers mimicking future climate change scenarios (mild, moderate and extreme), using a microcosm facility. $P$. simulans survived $(100 \%)$ to all scenarios after 30 days exposure, while $P$. axelrodi presented decreasing survival percentages according to environmental severity. These differences may be the reflection of distinct natural acclimatization to microhabitats between the species, which differ in thermal conditions. Survival responses might be related to differences in relative gene expression of lactate dehydrogenase (Ldh), suggesting that $P$. axelrodi anaerobic potential is lower or non-existent compared to $P$. simulans, not tolerating long-term thermal challenges. Accordingly, increases in temperature and in $\mathrm{CO}_{2}$ levels caused increases in energy demand and resulted in activation of the anaerobic pathway, as demonstrated by the higher enzyme levels measured in head and tail portions of both species. Sustained anaerobic glycolysis is possible when fish live in challenging environments (low oxygen or high temperature). Our results clearly show that $P$. simulans has a larger scope for survival to higher energy demands due to its increased anaerobic potential compared to $P$. axelrodi.
\end{abstract}

Keywords: ornamental fish, enzyme activity, relative gene expression, IPCC scenarios, Lactate Dehydrogenase (Ldh).

Received: January 26, 2017; Accepted: August 28, 2017.

\section{Introduction}

The review on lactate dehydrogenase (Ldh) tissue distribution in 245 fish species by Almeida-Val and Val (1993) suggested that hypoxia adaptation could be due to (i) predominance of isoform $\mathrm{B}_{4}$ in aerobic tissues, indicating permanent aerobic metabolism in tissues like heart and liver, and (ii) suppression of oxidative metabolism plus activation of anaerobic glycolysis, resulting in the predominance of isoform $\mathrm{A}_{4}$ in all tissues. The plasticity in regulating the expression of Ldh genes in fishes is one of the best biochemical adaptation processes to deal with oxygen and temperature environmental changes, besides the other ongoing impacts of climate change, as suggested by Hochach$\mathrm{ka}$ and Somero $(1973,2002)$. According to the IVth report of the Intergovernmental Panel for Climate Change (IPCC, 2007), the global atmospheric concentration of greenhouse gases (carbon dioxide, methane and nitrous oxide) has increased since the Industrial Revolution. Notably, carbon di-

Send correspondence to Vera Maria Fonseca de Almeida e Val. Brazilian National Institute for Research in the Amazon (INPA), Avenida André Araújo 2936, Petrópolis 69067-375 Manaus, AM, Brazil. E-mail address: veraval30@ gmail.com. oxide $\left(\mathrm{CO}_{2}\right)$ emissions increased from a pre-industrial level of approximately 280 parts per million (ppm) to over 400 ppm in 2016. Levels can increase to more than $800 \mathrm{ppm}$ at the end of the 21 st century, according Feely et al. (2004), reaching $1,250 \mathrm{ppm}$ in an extreme scenario (IPCC, 2007). Changes in anthropogenic activities such as fossil fuel and land use have driven global warming. The consequences of such changes deserve attention, particularly regarding the effects of increased temperature and carbon dioxide levels in the tropics, including the Amazon (Nobre et al., 2007, 2008).

Temperature, as a relevant environmental factor, can strongly affect fish physiology (Beitinger et al., 2000). Under elevated temperatures, energy demand increases, requiring several metabolic adjustments from the organism, such as those described for fishes of the Amazon (Almeida-Val and Hochachka, 1995; Driedzic and Almeida-Val, 1996). In many cases, fishes respond to temperature rise by Ldh genes transcription and enzyme levels increase, elevating the anaerobic power to cope with cellular hypoxia caused by higher metabolic demands (Almeida-Val et al., 2006; Heuton et al., 2015). Furthermore, elevated $\mathrm{CO}_{2}$ con- 
centrations tend to acidify the water (Guinotte and Fabry, 2008). Adverse short-term effects of high $\mathrm{CO}_{2}$ on fishes include respiratory and nervous system distress, imbalance of acid-base status, and changes in blood- $\mathrm{O}_{2}$ affinity (Ishimatsu et al., 2004). In addition, long-term high $\mathrm{CO}_{2}$ exposure causes reduced growth rate, reproduction disorders and death (Ishimatsu et al., 2005; Oliveira and Val, 2016).

Regional models of climate change indicate temperature increases between 2 and $6{ }^{\circ} \mathrm{C}$ in South America, as well as a decline in precipitation in eastern Amazonia (Ambrizzi et al., 2007; Salazar et al., 2007). Also, different climate models project a reduction of tropical forest cover, which might lead to a "savannization" in eastern Amazonia (Li et al., 2006; Salazar et al., 2007), affecting the biological conservation of terrestrial and aquatic ecosystems. Fish fauna diversity can be vulnerable to these challenges, particularly the commercially important, tiny ornamental fishes cardinal tetra (Paracheirodon axelrodi) (Schultz 1956) and green neon tetra (Paracheirodon simulans) (Géry 1963), analyzed in this study. P. axelrodi is the most exported Amazonian aquarium fishes (Anjos et al., 2009), which retain high microsatellite genetic variability and low genetic structure, even though they are intensely collected by extractive fisheries (Beheregaray et al., 2004; D'Assunção AAA, 2006, MSc. Thesis, Brazilian National Institute for Research of the Amazon, Manaus). These two congeneric species are endemic to the Amazon and occur in small streams that drain into Negro and Orinoco River basins (Axelrod et al., 1986). As observed by Marshall et al. (2011), the two species inhabit palm swamps with similar physicochemical conditions, though they have specific thermal preferences: the habitat of $P$. simulans reaches $35^{\circ} \mathrm{C}$, while the maximum temperatures of the $P$. axelrodi habitat roughly reach $29^{\circ} \mathrm{C}$.

Therefore, considering the differential thermal niches occupied by these two ornamental tetras and the similarities they share due to their contiguous environments and phylogeny, we anticipate differential responses to the nearfuture impacts of ongoing climate change, which may result in different ecological threats. In the present work, we tested the influence of three different IPCC scenarios projected for the year 2100, based on the Special Report on Emission Scenarios (SRES), to both $P$. axelrodi and $P$. simulans to understand how they respond to forecasted climate change.

\section{Material and Methods}

This study followed the Brazilian Guidelines from the National Board of Control and Care for Ethics in the use of Experimental Animals (CONCEA/MCTI) and was approved by the INPA's Committee of Ethics on Animal Care (Protocol 024/2012). Voucher specimens were deposited at INPA's Fish Collection (38.318 for P. axelrodi and 38.319 for P. simulans).

\section{Sampling and maintenance of fish}

Adult specimens of $P$. axelrodi and $P$. simulans purchased in a local ornamental fish shop (Prestige Aquarium LTDA) were transported to the Laboratory of Ecophysiology and Molecular Evolution (CBIO/INPA) and kept indoors for 30 days in $150 \mathrm{~L}$ polystyrene tanks under constant aeration. The animals were fed ad libitum with commercial dry food pellets ( $35 \%$ protein content).

\section{Experimental setup: climate change simulations in microcosms}

Both species were exposed to three climate scenarios foreseen by IPCC (2007), aiming to investigate the effects of climate change on fish's survival and the activation of their anaerobic metabolism (Ldh gene expression and enzyme activity). Temperature, $\mathrm{CO}_{2}$ concentration, air humidity, and photoperiod were automatically controlled in environmental rooms (microcosms) under a real-time protocol (Dragan F, Gutierrez D, Oliveira A, Almeida-Val V and Val A, unpublished), according to three main scenarios: mild scenario or $\mathrm{B} 1\left(+1.5{ }^{\circ} \mathrm{C}\right.$ and $+200 \mathrm{ppm} \mathrm{CO} \mathrm{CO}_{2}$ over the current scenario); moderate scenario or A1B $\left(+2.5^{\circ} \mathrm{C}\right.$ and $+400 \mathrm{ppm} \mathrm{CO}_{2}$ over the current scenario); and extreme scenario or $\mathrm{A} 2\left(+4.5^{\circ} \mathrm{C}\right.$ and $+850 \mathrm{ppm} \mathrm{CO} \mathrm{CO}_{2}$ over the current scenario). The control room mimics the temperature and $\mathrm{CO}_{2}$ levels of a pristine forest nearby the laboratory. A Proportional Integral Derivative system monitored and adjusted the environmental parameters every other minute in each microcosm based on the control room (current scenario). Light-dark cycle was set to $12: 12 \mathrm{~h}$ and humidity was set as derived condition.

\section{Exposure to forecasted climate scenarios for the year of 2100}

Two hundred specimens of $P$. axelrodi $(0.09 \pm$ $0.004 \mathrm{~g}$ and $2.1 \pm 0.03 \mathrm{~cm})$ and $P$. simulans $(0.06 \pm 0.008 \mathrm{~g}$ and $1.7 \pm 0.03 \mathrm{~cm}$ ) were transferred to each of the eight plastic aquaria $(18 \mathrm{~L})$. Fish remained in aerated water and were incubated in the four microcosms as mentioned above (one aquarium per species per room). Average water temperature, $\mathrm{pH}$, and dissolved oxygen were measured daily before transferring the aquaria of both species to the microcosms. For $P$. axelrodi, aquaria temperature, $\mathrm{pH}$ and dissolved oxygen were $26.63 \pm 0.12{ }^{\circ} \mathrm{C}$; $\mathrm{pH} 6.50 \pm 0.38$ and $6.39 \pm 0.23 \mathrm{mgO}_{2} \mathrm{~L}^{-1}$, respectively. For $P$. simulans, water conditions were $26.67 \pm 0.12{ }^{\circ} \mathrm{C} ; \mathrm{pH} 6.48 \pm 0.20$ and $5.81 \pm$ $0.24 \mathrm{mgO}_{2} \mathrm{~L}^{-1}$.

After one-week artificial acclimatization, all experimental aquaria were transported to the baseline scenario (control room) and sequentially (each $48 \mathrm{~h}$ ) transferred to the next microcosm with previously set climate scenarios. Fish were sampled at two and 30 days after being transferred to a given microcosm. For each exposure, 48 individuals of $P$. axelrodi and $P$. simulans (twelve fish per species, 
per climate scenario) were carefully collected using a sterile tweezer and immediately stored in liquid nitrogen until RNA extractions and enzyme assays. Ultra-rapid freezing of the animals by direct immersion in liquid nitrogen $\left(-180^{\circ} \mathrm{C}\right)$ was the physical euthanasia method performed according to the Brazilian CONCEA guidelines for minute ornamental fishes.

Each aquarium had water quality checked twice a day over the experimental period using a digital oxygen meter YSI (Yellow Springs Instruments) model 55/12 for temperature and dissolved oxygen, a digital $\mathrm{pH}-m$ eter UltraBASIC UB-10 (Denver Instrument Co.), and a colorimetric method for carbon dioxide concentration (Boyd and Tucker, 1992). The water of aquaria was partially (50\%) renewed every other day. Survival percentages were measured by counting fish with signs of pre-death, i.e., erratic swimming behavior or loss of equilibrium (LOE). These animals were removed from the experimental aquaria, euthanized and appropriately discarded.

RNA extraction, cDNA synthesis, sequencing, and primer design

Whole fish from each tetra species $(n=6)$ were homogenized in $500 \mu \mathrm{L}$ of TRIzol Reagent (Life Technologies) according to the manufacturer's instructions for total RNA extraction. We used a NanoDrop 2000 Spectrophotometer (Thermo Fisher Scientific) to check concentration and quality of extracted RNA, and electrophoresis on $1 \%$ agarose formaldehyde gel to verify RNA integrity. We used DNase I (Life Technologies) to degrade genomic DNA in RNA samples. Synthesis of cDNA was obtained by reverse transcription reaction using RevertAid $\mathrm{H}$ Minus First Strand cDNA Synthesis kit (Fermentas), following the manufacturer's instructions. Partial sequences of $l d h-a$, $l d h-b$, and $18 S$ genes were obtained using primers previously designed from a conserved region of other teleost fishes available in the GenBank database. The $l d h-a, l d h-b$, and $18 S$ primer sequences were: 5'-GG(A/T) GCC CG(C/T) CAG CAG GA-3' (forward) and 5'-ATG GCC CAG GA(G/A) GTG TAG CC-3' (reverse); 5'-TGG GAG TGG GGC AAG TGG GC-3' (forward) and 5'-ACT GTG
TTT GAC GAT CTG AGG-3' (reverse); and 5'-GGA ATG AGT ACA CTT TAA ATCC-3' (forward) and 5'-GGG GCG CCG AGA GGC AGG GGC-3' (reverse), respectively. All PCR products were sequenced with $1 \mu \mathrm{L}$ of Big Dye fluorescent dye (Applied Biosystems) and run on an ABI 3130XL automatic DNA sequencer (Applied Biosystems). The acquired partial nucleic acid sequences (Table S1) were analyzed using the BLAST program at the National Center for Biotechnology Information (NCBI) website and then used to generate $P$. axelrodi and $P$. simulans specific qRT-PCR primers.

\section{Quantitative real-time PCR}

RNA extraction from 96 individuals (48 P. axelrodi and 48 P. simulans) and the synthesis of the first strand cDNA followed the method of reverse transcription, as mentioned above. The $l d h-a$ and $l d h-b$ relative gene expression were assessed by quantitative real-time PCR (qRTPCR) on an ABI Prism 7500 sequence detection system (Applied Biosystems). Table 1 shows the primer pairs for all genes from both species, which were designed using Oligo Explorer software version 1.1.2 (free software developed by Teemu Kuulasmaa). Real-time PCR reactions were performed using $1 \mu \mathrm{L}$ of cDNA (concentration of $1 \mu \mathrm{g}), 1 \mu \mathrm{L}$ of each primer (concentration $2.5 \mathrm{pM}$ ), $2 \mu \mathrm{L}$ of nuclease-free water (Life Technologies) and $5 \mu \mathrm{L}$ of SYBR Green PCR Master Mix (Applied Biosystems) in a total volume of $10 \mu \mathrm{L}$. The following conditions were used: $2 \mathrm{~min}$ at $50{ }^{\circ} \mathrm{C}$ and an initial denaturation step at $95^{\circ} \mathrm{C}$ for $10 \mathrm{~min}$, followed by 40 cycles of $95^{\circ} \mathrm{C}$ for $15 \mathrm{~s}$, and $60^{\circ} \mathrm{C}$ for $1 \mathrm{~min}$ (annealing temperature of all primers). Melting curve analyses done after running the PCR protocol confirmed the presence of a single product-specific melting temperature, as follows: $P$. axelrodi $-l d h-a, 76.8^{\circ} \mathrm{C}$; ldh- $b$, $78.8^{\circ} \mathrm{C}$ and $18 S, 81.1^{\circ} \mathrm{C}$; and $P$. simulans $-l d h-a, 77.1^{\circ} \mathrm{C}$; $l d h-b, 81.2^{\circ} \mathrm{C}$ and $18 S, 81.5^{\circ} \mathrm{C}$. PCR amplification efficiency for each primer set was calculated by serial dilution curves obtained from a pool of experimental samples ( 1 to $0.001 \mu \mathrm{g}$ cDNA concentration; $n=6$ ). All primer pairs showed optimal PCR efficiency: 2.0 for $l d h-a$ and $18 S$ and 1.99 for $l d h-b$ of $P$. axelrodi; and 1.95 for $l d h-a, 1.98$ for

Table 1 - Quantitative real-time PCR primer sets for Paracheirodon axelrodi and P. simulans.

\begin{tabular}{|c|c|c|c|c|}
\hline Gene & Forward primer $\left(5^{\prime}-3^{\prime}\right)$ & Reverse primer $\left(5^{\prime}-3^{\prime}\right)$ & Length (bp) & Amplicon length (bp) \\
\hline \multicolumn{5}{|c|}{ P. axelrodi } \\
\hline$l d h-a$ & TCAGATCGTCAAGTACAGCC & AACTTCCAGGTGACGTAGGT & 20 & 84 \\
\hline$l d h-b$ & TAGTCCTTGTCAGCCACGAT & AGGGACTTGTGTGATGAGCT & 20 & 126 \\
\hline $18 S$ & GGAACCCAAAGACTCTGGT & TAATCAAGAACGAAAGTCGG & 19 & 144 \\
\hline \multicolumn{5}{|c|}{ P. simulans } \\
\hline$l d h-a$ & TAACGGGTACATCTTGGGAG & GGCTAACTCCAGCAACGTTA & 20 & 77 \\
\hline$l d h-b$ & AGATGTTGACGTTCCTCTGC & ACTCTGTGACCGCTAACTCC & 20 & 102 \\
\hline $18 S$ & ACCCAAAGACTCTGGTTTCC & AGATACCGTCGTAGTTCCGA & 20 & 104 \\
\hline
\end{tabular}


$18 S$ and 1.97 for $l d h-b$ for $P$. simulans, as well as a high Pearson correlation coefficient $(\mathrm{r}>0.95)$.

The relative transcript levels of the target genes were calculated by a comparative $\mathrm{Ct}$ method using the $2^{-\Delta \Delta C t}$ formula (Livak and Schmittgen, 2001). The relative quantification of each gene was normalized to a reference gene $(18 S)$ and expressed relative to a calibrator sample, where $\Delta \Delta C_{\mathrm{t}}=\left[\Delta C_{t, \text { target (sample) }}-\Delta C_{t, 18 S \text { (sample) }}\right]-\left[\left(\Delta C_{t, \text { target (calibrator }}\right.\right.$

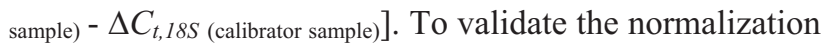
calculations, we previously confirmed $18 S$ as a suitable internal control gene due its uniform efficiency and stable expression under experimental climate scenarios (one-way ANOVA, $P>0.05$ ). In addition, $18 S$ ribosomal RNA has been used as endogenous reference gene in previous studies with Amazonian fish (Anjos et al., 2011; Baptista et al., 2016; Vásquez KL, 2009, PhD Thesis, Federal University of Amazonas, Manaus; Oliveira CPF, 2010, PhD Thesis, Federal University of Amazonas, Manaus). An untreated control from the baseline scenario was selected as a calibrator sample for qRT-PCR relative quantification assays.

\section{Enzyme activity}

Absolute activities of lactate dehydrogenase (EC 1.1.1.27, L-lactato: $\mathrm{NAD}^{+}$oxidoreductase) were measured at $340 \mathrm{~nm}$, according to Driedzic and Almeida-Val (1996) with modifications, using a microplate reader SpectraMax Plus 384 (Molecular Devices). As the small size of tetras requires the use of a magnification lens to collect separate organs, imposing a longer time to process the samples, 48 individuals of each species were transversely divided into two portions: head (brain, heart, and liver) and tail (mostly white muscle). Each portion represents the differential contribution of the two Ldh genes: the head portion is expected to have a dominance of the $l d h-b$-like isoform, and the tail portion a dominance of the $l d h$ - $a$-like isoform, as previously described for many other teleost species (Whitt et al., 1973; Almeida-Val and Val, 1993). Both body portions (or sides) were manually homogenized in an ice-cold buffer solution containing $150 \mathrm{mM}$ imidazole, $1 \mathrm{mM}$ EDTA and $1 \%$ Triton X-100 (pH 7.4) in a tissue/buffer ratio 1:10 $(\mathrm{w} / \mathrm{v})$. Homogenates were centrifuged at $15,000 \times \mathrm{x}$ for $15 \mathrm{~min}$ at $4{ }^{\circ} \mathrm{C}$. The assay mixture consisted of $0.15 \mathrm{mM}$ $\mathrm{NADH}$ and $50 \mathrm{mM}$ imidazole, $\mathrm{pH} 7.4$ at $25^{\circ} \mathrm{C}$. All reactions were initiated by the addition of $1 \mathrm{mM}$ pyruvate as the low substrate concentration (Hochachka et al., 1978). The high pyruvate concentration $(10 \mathrm{mM})$ was also used to measure low/high $(\mathrm{L} / \mathrm{H})$ pyruvate activity ratios as described in Bailey and Wilson (1968). L/H values were calculated as the ratio between the activity obtained with $1 \mathrm{mM}$ pyruvate and that obtained with $10 \mathrm{mM}$. An L/H > 1.0 indicates $\mathrm{Ldh}$ inhibition (favoring aerobic metabolism and $\mathrm{Ldh}-\mathrm{B}_{4}$ predominance), whereas an $\mathrm{L} / \mathrm{H} \leq 1.0$ indicates non-inhibition of Ldh (supporting anaerobic metabolism and Ldh- $\mathrm{A}_{4}$ predominance). Ldh activity is expressed as $\mu$ mol pyruvate $\cdot \min ^{-1} \cdot g$ wet tissue ${ }^{-1}$.

\section{Statistical analysis}

Relative gene expression and Ldh activity are presented as mean \pm SEM (standard errors of means; $n=4-6$ ). Mean differences were evaluated by two-way ANOVA with scenarios $(d f=3)$ and acclimatization time $(d f=1)$ as factors, followed by Bonferroni multiple comparisons post-hoc tests. A significant difference was assumed when $P<0.05$. SigmaStat version 3.5 was used for statistical analysis, and graphs were built using SigmaPlot version 11.0 .

\section{Results}

\section{Experimental conditions}

Real-time changes in temperature and $\mathrm{CO}_{2}$ levels in the three microcosms followed the environmental conditions in the control room over the experimental period (Figure S1). We observed no variation (one-way ANOVA; $F=0.158, d f=3, P=0.925)$ in air humidity between the current (61.74 \pm 1.63$)$, mild (60.80 \pm 1.49$)$, moderate (60.29 \pm $1.39)$, and extreme $(60.89 \pm 1.50)$ scenarios.

Water quality of experimental tanks is described in Table 2. Significant increases in temperature and $\mathrm{CO}_{2}$ concentration in the water were observed, showing the effectiveness of the microcosm experimental setup. The minor decrease in dissolved oxygen concentrations in experimental tanks of the mild scenario did not represent a hypoxic situation for the studied species (Oliveira et al., 2008; Marshall et al., 2011; Campos et al., 2016).

\section{Fish survival}

Survival percentages were different between the two species and among scenarios for P. axelrodi (Figure 1); increasing mortality was observed for $P$. axelrodi according the severity of the climate scenarios.

\section{Relative expression of Ldh genes}

Anaerobic responses, measured as transcripts of $l d h-a$ and $l d h-b$ genes, were different in both species. While no clear correlated responses of gene transcription to climate severity were observed for $P$. axelrodi (Figure 2), $P$. simulans exhibited a direct increase of $l d h-a$ and $l d h-b$ transcription according to the severity of the experimental climate scenarios (Figure 3). Post-hoc comparisons showed an immediate increase in $l d h-a$ transcription (approximately 25 -fold) in $P$. axelrodi specimens exposed for two days to the mild scenario compared with the baseline scenario $(F=5.016, P<0.001)$; and a 192-fold decrease after 30 days in the mild scenario $(F=4.855, P<0.001)$ (Figure $2 \mathrm{~A})$. Furthermore, $l d h-b$ mRNA levels increased 72 -fold in this species when exposed for 30 days to the moderate scenario, compared to fish in baseline scenario $(F=7.810, P<0.001)$, and increased 108-fold compared to fish acclimated for two 
Table 2 - Temperature, carbon dioxide, oxygen and $\mathrm{pH}$ of the water used for fish exposure in the microcosms (at day 30 )

\begin{tabular}{|c|c|c|c|c|}
\hline Emission Scenario & Temperature $\left({ }^{\circ} \mathrm{C}\right)$ & $\mathrm{CO}_{2}(\mathrm{ppm})$ & Dissolved oxygen $\left(\mathrm{mgL}^{-1}\right)$ & $\mathrm{pH}$ \\
\hline \multicolumn{5}{|l|}{ P. axelrodi } \\
\hline \multirow[t]{2}{*}{ Current } & $27.63 \pm 0.22$ & $15.22 \pm 1.57$ & $6.96 \pm 0.14$ & $5.55 \pm 0.11$ \\
\hline & $(25.1-29.3)$ & $(5-29)$ & $(4.62-8.53)$ & $(4.86-8.02)$ \\
\hline \multirow[t]{2}{*}{ Mild } & $29.22 \pm 0.23 *$ & $19.55 \pm 1.64$ & $6.23 \pm 0.12 *$ & $5.62 \pm 0.14$ \\
\hline & $(26.5-30.9)$ & $(10,4-29)$ & $(4.9-7.44)$ & $(4.29-8.6)$ \\
\hline \multirow[t]{2}{*}{ Moderate } & $29.960 .25^{*}$ & $24.21 \pm 1.77$ & $6.89 \pm 0.11$ & $5.46 \pm 0.09$ \\
\hline & $(27.1-32)$ & $(9-56)$ & $(5.85-8.68)$ & $(4.89-7.59)$ \\
\hline \multirow[t]{2}{*}{ Extreme } & $31.53 \pm 0.19^{*}$ & $34.06 \pm 3.22 *$ & $6.55 \pm 0.10$ & $5.22 \pm 0.11$ \\
\hline & $(29.3-32.9)$ & $(7-78)$ & $(5.5-8.05)$ & $(4.27-7.86)$ \\
\hline \multicolumn{5}{|l|}{ P. simulans } \\
\hline \multirow[t]{2}{*}{ Current } & $27.80 \pm 0.22$ & $15.10 \pm 1.92$ & $6.90 \pm 0.17$ & $5.76 \pm 0.11$ \\
\hline & $(24.7-29.6)$ & $(5,5-34)$ & $(4.87-8.61)$ & $(4.56-7.98)$ \\
\hline \multirow[t]{2}{*}{ Mild } & $29.36 \pm 0.23 *$ & $18.02 \pm 1.57$ & $5.50 \pm 0.12 *$ & $5.81 \pm 0.07$ \\
\hline & $(26.7-31.2)$ & $(7-32)$ & $(4.65-6.92)$ & $(5.05-7.19)$ \\
\hline \multirow[t]{2}{*}{ Moderate } & $30.43 \pm 0.23 *$ & $22.82 \pm 1.79$ & $6.47 \pm 0.15$ & $5.64 \pm 0.08$ \\
\hline & $(27.5-32.1)$ & $(8-35)$ & $(4.98-8.27)$ & $(5.21-7.78)$ \\
\hline \multirow[t]{2}{*}{ Extreme } & $32.20 \pm 0.22 *$ & $33.52 \pm 3.64 *$ & $6.49 \pm 0.12$ & $5.45 \pm 0.10$ \\
\hline & $(29.6-33.8)$ & $(16-60)$ & $(5.42-7.87)$ & $(4.32-7.62)$ \\
\hline
\end{tabular}

${ }^{\mathrm{a}}$ Data are shown as mean $\pm \mathrm{SEM}$; minimum and maximum values in parenthesis. Sample size for each parameter: $n=30$ for each experimental aquarium. *Significant differences from current scenario (one-way ANOVA, $P<0.05$ ).

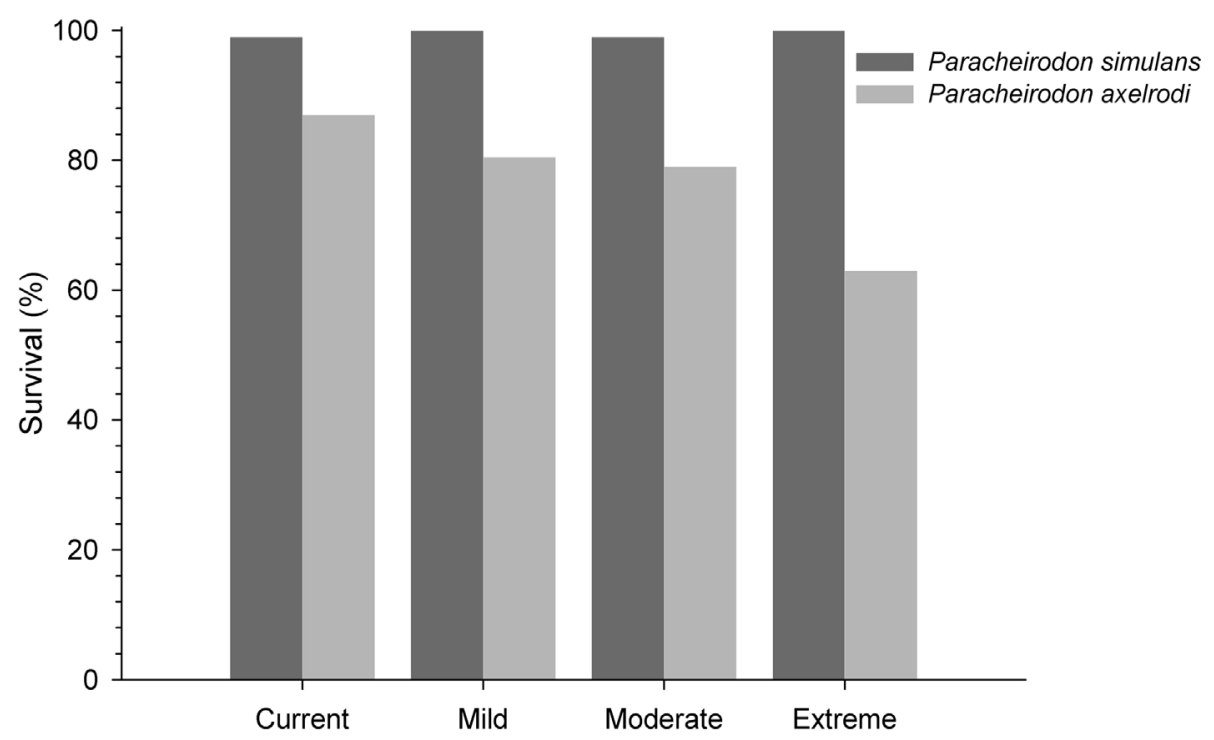

Figure 1 - Survival (\%) of Paracheirodon axelrodi and $P$. simulans artificially acclimatized in climate change scenarios. Fish were exposed for 30 days in current, mild, moderate and extreme scenarios simulated in the microcosms.

days under the same scenario $(F=8.388, P<0.001)$ (Figure 2B).

Post-hoc comparisons for $P$. simulans showed an increase in $l d h-a$ transcription rates among climate scenarios and over the acclimatization periods: approximately $14-$ fold in mild $(F=2.683, P=0.009)$ and moderate $(F=4.617, P$
$<0.001)$ scenarios, and 180 -fold in the extreme scenario $(F=6.276, P<0.001)$. When compared with the baseline scenario, ldh- $a$ expressed as follows: 5-fold increase in the mild ( $F=3.084, P=0.016$ ), 8 -fold increase in the moderate $(F=3.922, P=0.001)$, and 11-fold increase in the extreme emission scenario $(F=5.106, P<0.001)$ (Figure $3 \mathrm{~A})$. Fish 

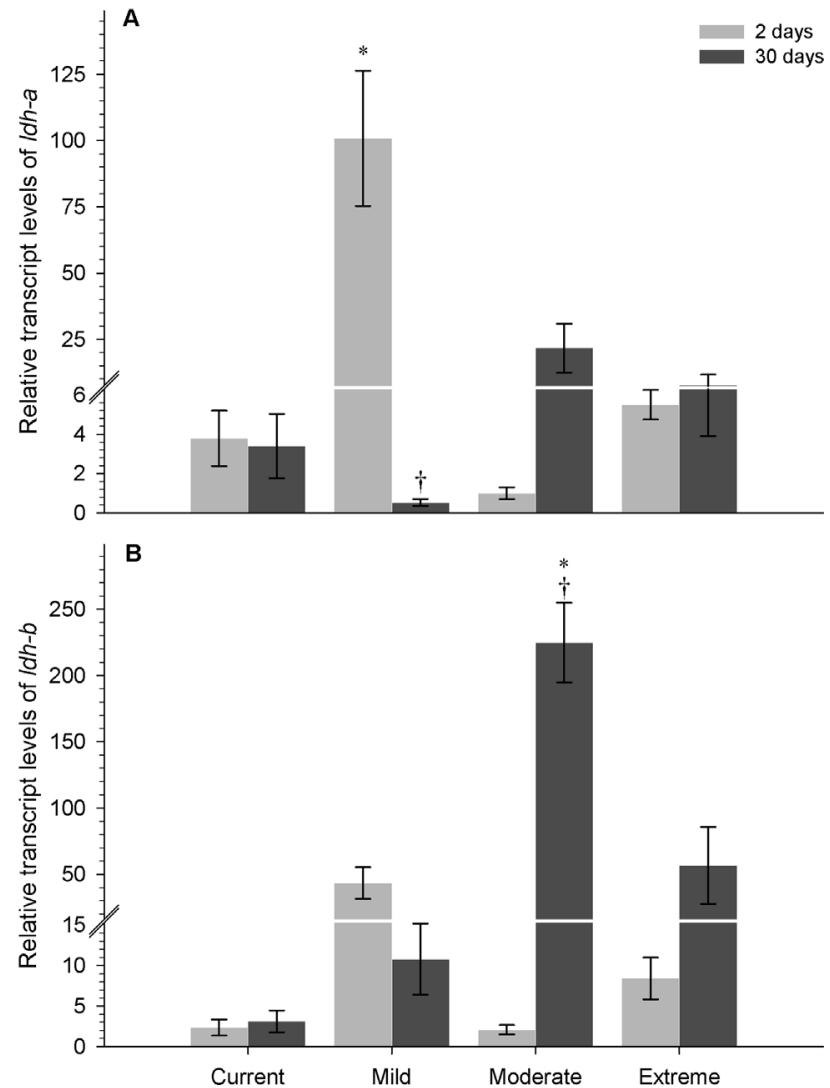

Figure 2 - Relative expression of Ldh genes in $P$. axelrodi. Differential transcript levels of $l d h-a(\mathrm{~A})$ and $l d h-b(\mathrm{~B})$ after 2 and 30 days in current, mild, moderate and extreme climate scenarios. Data are reported as mean \pm SEM. Sample sizes for both genes: $N=4$. *Significant differences from current scenario; $\uparrow$ Significant differences between acclimatization times within a given scenario (two-way ANOVA, $P<0.05$ ).

exposed for 30 days to the three IPCC scenarios showed higher levels of $l d h-b$ transcription compared to the baseline scenario, reaching a 20 -fold increase at the extreme scenario compared with control $(F=8.181, P<0.001)$ and a 103 -fold increase compared with fish acclimated for two days under similar conditions $(F=9.703, P<0.001)$ (Figure 3B).

The ratios between the transcriptions of the two target genes $(l d h-a / l d h-b)$ confirmed the quick response of these anaerobic isoform genes (Figure 4). A similar profile appeared for both species; ldh-a/ldh-b values rapidly increased in fish exposed for two days to all climate scenarios, subsequently stabilizing in fish exposed for 30 days, particularly at mild (Student's t-test; $t=3.011, d f=19$, $P=0.007$ for $P$. axelrodi; $t=3.073, d f=19, P=0.006$ for $P$. simulans) and moderate (Student's $t$-test; $t=3.918, d f=19$, $P=<0.001$ for $P$. axelrodi; $t=2.461, d f=24, P=0.021$ for $P$. simulans) scenarios.

\section{Enzyme activities}

Similarly to gene transcription, $\mathrm{Ldh}$ activities of both body portions of tetras responded to the tested climate sce-
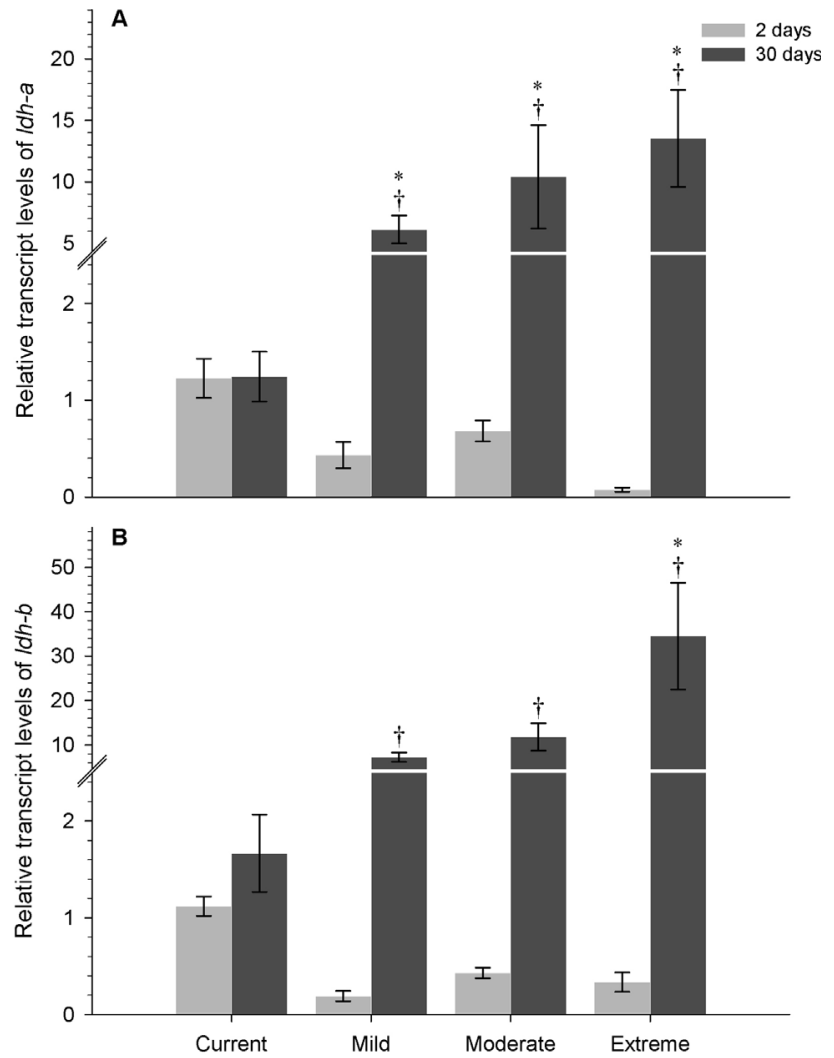

Figure 3 - Relative expression of Ldh genes in P. simulans. Differential transcript levels of $l d h-a$ (A) and $l d h-b$ (B) after 2 and 30 days in current, mild, moderate and extreme climate scenarios. Data are reported as mean \pm SEM. Sample sizes for both genes: $N=4$. *Significant differences from current scenario; $\uparrow$ Significant differences between acclimatization times within a given scenario (two-way ANOVA, $P<0.05$ ).

narios as well as to time of artificial acclimatization $(P<$ 0.05 ) (Table 3). P. axelrodi individuals exposed for two days to moderate and extreme scenarios presented, respectively, a significant increase in Ldh activity in head $(F=3.430, P=0.001 ; F=2.632, P=0.012)$ and tail $(F=5.396$, $P<0.001 ; F=4.921, P<0.001$ ) portions when compared to the fish under the baseline scenario. After 30 days, enzyme activity in head and tail changed, respectively, in a similar way; i.e., significantly increased in fish exposed to control $(F=2.461, \quad P=0.018 ; \quad F=3.197, \quad P=0.003) \quad$ and mild ( $F=0,332, P=0.05 ; F=2.153, P=0.037)$ scenarios, and decreased at moderate $(F=2.966, \quad P=0.005 ; \quad F=3.437$, $P=0.001)$ and extreme $(F=2.224, P=0.032 ; \quad F=2.987$, $P=0.006$ ) scenarios.

Regarding $P$. simulans, we observed a significant increase in Ldh activity in head and tail portions of animals exposed for two days to the extreme and moderate scenarios comparing to the current one $(F=2.163, P=0.037$; $F=3.443, P=0.001)$. However, fish artificially acclimatized for 30 days presented a decrease in Ldh values in the head portion in moderate scenario $(F=2.519, P=0.016)$, and in the tail portion of fish under the extreme scenario $(F=2.822$, $P=0.007$ ), compared to two-day exposure. 

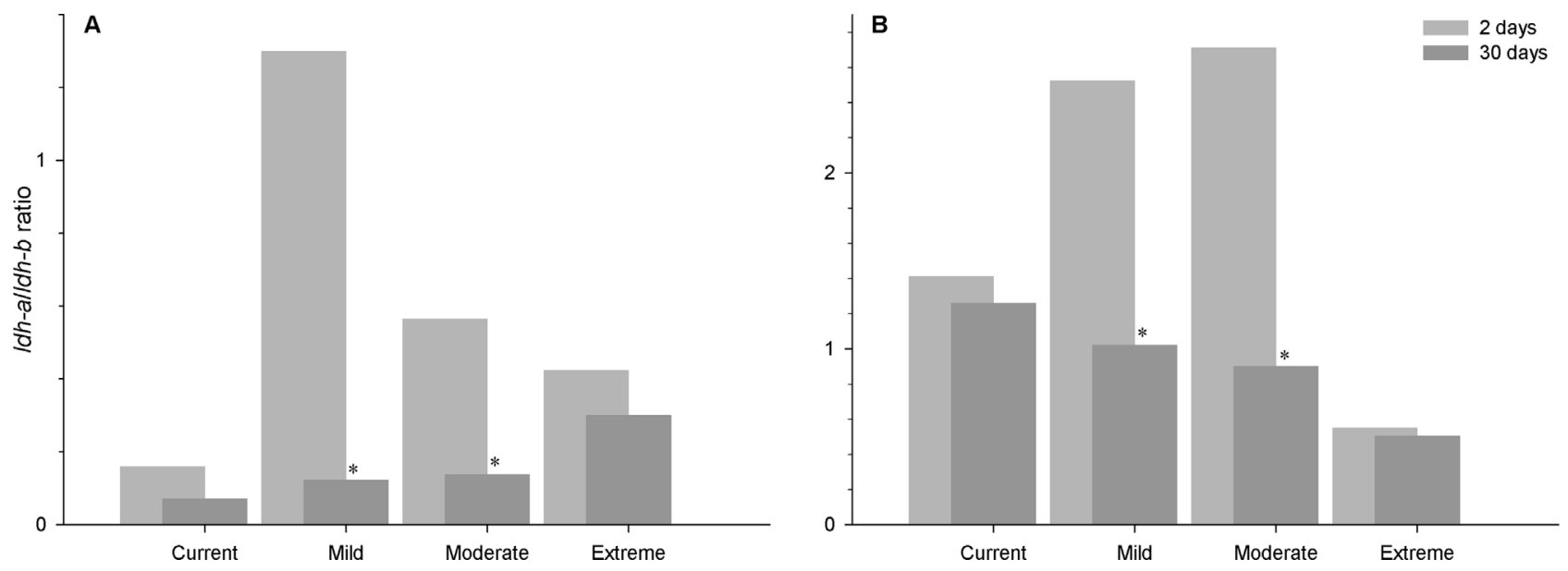

Figure 4 - $l d h$ - $a / l d h$ - $b$ ratios in $P$. axelrodi (A) and $P$. simulans (B) artificially acclimatized for 2 and 30 days in current, mild, moderate and extreme scenarios. All data are reported as means. Sample sizes are given in Figures 2 and 3. *Significant differences between acclimatization times within a given scenario (Student's $t$-test, $P<0.05$ ).

Table 3 - Lactate dehydrogenase (Ldh) activity (1 mM pyruvate) predominant in head and tail portions of Paracheirodon axelrodi and $P$. simulans acclimated for two and 30 days at climate scenarios simulated in the microcosms $\mathrm{s}^{\mathrm{a}}$.

\begin{tabular}{|c|c|c|c|c|}
\hline \multirow[t]{2}{*}{ Emission Scenario } & \multicolumn{2}{|c|}{ Head portion } & \multicolumn{2}{|c|}{ Tail portion } \\
\hline & 2 days & 30 days & 2 days & 30 days \\
\hline \multicolumn{5}{|l|}{ P. axelrodi } \\
\hline Current & $55.97 \pm 1.43$ & $60.74 \pm 1.38$ & $58.67 \pm 0.79$ & $66.84 \pm 3.36$ \\
\hline Mild & $57.47 \pm 0.96$ & $60.68 \pm 1.15$ & $59.40 \pm 0.71$ & $66.00 \pm 2.22$ \\
\hline Moderate & $64.03 \pm 1.20^{*}$ & $58.90 \pm 0.63$ & $70.78 \pm 5.88^{*}$ & $60.37 \pm 0.17$ \\
\hline Extreme & $63.32 \pm 0.91 *$ & $58.99 \pm 0.26$ & $67.11 \pm 1.10^{*}$ & $60.19 \pm 0.59$ \\
\hline \multicolumn{5}{|l|}{ P. simulans } \\
\hline Current & $47.19 \pm 2.79$ & $48.02 \pm 1.20$ & $59.70 \pm 0.59$ & $61.79 \pm 3.28$ \\
\hline Mild & $46.46 \pm 1.07$ & $49.04 \pm 2.31$ & $57.70 \pm 1.08$ & $59.54 \pm 0.46$ \\
\hline Moderate & $55.45 \pm 1.82$ & $50.75 \pm 1.47$ & $62.68 \pm 1.08^{*}$ & $57.87 \pm 0.43$ \\
\hline Extreme & $52.33 \pm 1.32 *$ & $45.55 \pm 0.35$ & $63.83 \pm 0.53$ & $60.56 \pm 0.66$ \\
\hline
\end{tabular}

${ }^{a} \mathrm{Ldh}$ activity is reported as $\mu \mathrm{mol}$ pyruvate $\cdot \mathrm{min}^{-1} \cdot \mathrm{g}$ wet tissue ${ }^{-1}$ (mean $\pm \mathrm{SEM}$ ). Sample size for each tetra species: $N=6$. $*$ Significant differences from current scenario; Significant differences between acclimatization times within a given scenario (two-way ANOVA, $P<0.05$ ).

Low/high $(\mathrm{L} / \mathrm{H})$ ratios obtained in the head and tail portions of both species after exposure to the analyzed climate scenarios are presented in Figure 5. The values were equal to, or lower than 1.0, indicating activation of Ldh at higher pyruvate concentration $(10 \mathrm{mM})$ and, therefore, the increase of anaerobic glycolysis in all fish portions. These data also confirm the predominance of Ldh- $\mathrm{A}_{4}$ isoforms in both body portions: head portion values ranged from 0.84 to 1.08 , and tail portions from 0.72 to 1.02 .

\section{Discussion}

Daily and seasonal variations of physicochemical parameters of aquatic environments such as fluctuations in temperature cause multiple physiological effects on fishes, influencing several ecological characteristics, including their natural distribution (Beitinger et al., 2000; SchmidtNielsen, 2002). P. axelrodi and $P$. simulans inhabit thermally distinct habitats in the middle region of the Negro river, as observed by Marshall et al. (2011). The minimum and maximum daily water temperatures in their microhabitats range from $25.1^{\circ} \mathrm{C}$ to $29.9^{\circ} \mathrm{C}$ for P. axelrodi, and from $24.6{ }^{\circ} \mathrm{C}$ to $35.2{ }^{\circ} \mathrm{C}$ for $P$. simulans. The higher water temperature in $P$. simulans natural habitats suggests a better thermal tolerance of this species to higher temperatures. Campos et al. (2016) described their differential thermal tolerance through the Thermal Tolerance Polygons, suggesting that they present maximum and minimum thermal limits according to their differential responses to acclimation temperatures. Thus, they suggested that $P$. simulans tolerates higher temperatures compared to $P$. axelrodi. The 

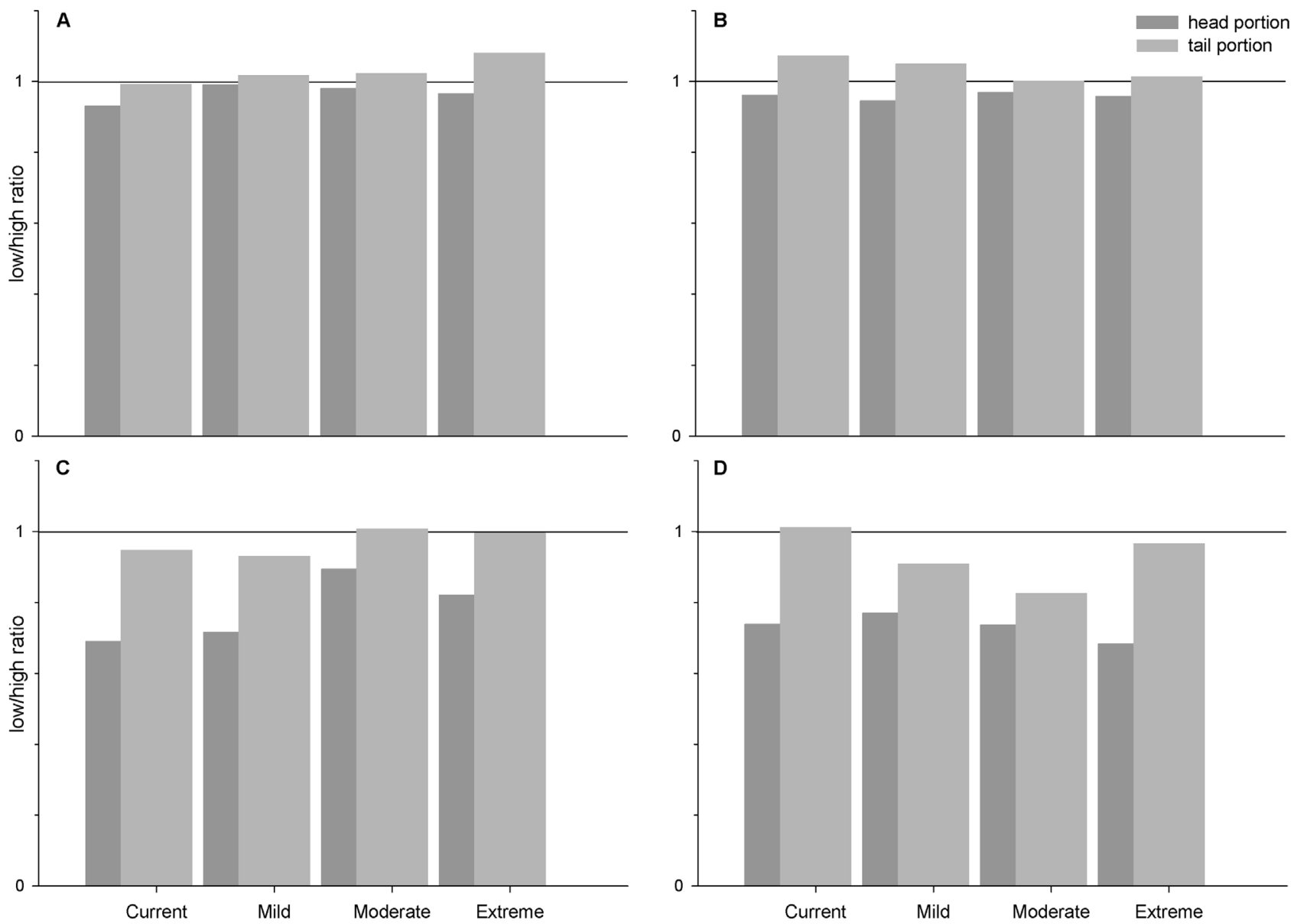

Figure 5 - Low/high ratios in head and tail portions of both species. P. axelrodi (A and B) and P. simulans (C and D). Fish were acclimatized for two days $(\mathrm{A}$ and $\mathrm{C})$ and 30 days $(\mathrm{B}$ and $\mathrm{D})$ at climate scenarios. The values represent ratios and all data are reported as means.

data herein described confirm a better ability of $P$. simulans to support higher temperatures once this species exhibited $100 \%$ survival in all three tested climate scenarios. Instead, $P$. axelrodi presented a decreased survival according to the severity of the climate scenarios, reaching only $67 \%$ at the extreme scenario (Figure 1). The adaptation to their natural environmental niches must account for their differential acclimatization at these artificial climate scenarios set as foreseen by IPCC for the year 2100. The effective temperature in each of the species natural microenvironment resulted in different metabolic responses, including differential $P_{\text {crit }}$ values, which accounts for differential hypoxia tolerance as well (Campos et al., 2016). The differences found in survival responses are just a glance (30-day exposure) of what may occur in the many generations until the year 2100 . However, the data suggest that mortality may occur shortly if fish do not adapt through gene plasticity (epigenetic changes, for instance) or selection of favoring mutation in enzymes/proteins. Furthermore, the velocity in which the changes are occurring could be a severe threat to all living species, since evolutionary responses and adaptation to an environmental change might require a much longer time range.
Previous studies addressing lethal temperatures of $P$. axelrodi $\left(\mathrm{LT}_{50}, 96 \mathrm{~h}=33.7^{\circ} \mathrm{C}\right)$ resulted in $100 \%$ fish survival between 29 and $31^{\circ} \mathrm{C}$, reaching total fish mortality at temperatures above $35^{\circ} \mathrm{C}$ (Oliveira et al., 2008). The recent study by Campos et al. (2016) described the minimum and maximum thermal limits for both species, using critical thermal methodology (CTM): 13 to $40{ }^{\circ} \mathrm{C}$ for $P$. axelrodi and 12 to $42{ }^{\circ} \mathrm{C}$ for $P$. simulans. Thus, as we observed in the present work, $P$. simulans tolerated a wider temperature range than $P$. axelrodi. Prodocimo and Freire (2001) reported similar results for the tropical platyfish Xiphophorus maculatus, an ornamental freshwater teleost. They determined the thermal tolerance limits ranging from a minimum of $9.6^{\circ} \mathrm{C}$ to a maximum of $41.5^{\circ} \mathrm{C}$, showing the greater capacity of tropical species to withstand high temperatures better than low ones.

Herein, both $P$. axelrodi and $P$. simulans adapted to high temperatures (Axelrod et al., 1986), although $P$. simulans tolerated a higher range compared to $P$. axelrodi. As mentioned, Campos et al. (2016) demonstrated that $P$. simulans is also more tolerant to hypoxia, indirectly measured by critical oxygen tension $\left(P_{\text {crit }}\right)$, and exhibits higher metabolic rates than $P$. axelrodi, what explains its greater 
ability to tolerate high temperatures. A recent study by McBryan et al. (2016) showed that warm acclimation of two Fundulus heteroclitus subspecies (southern-warm and northern-cold) improves their hypoxia tolerance. They also showed different measurements of $\mathrm{LOE}_{\text {hyp }}$ (loss of equilibrium in hypoxia), critical oxygen tension $\left(P_{\text {crit }}\right)$ and total lamellar surface area in warm acclimated fish. Warm acclimation caused different hypoxia tolerance levels between the two subspecies suggesting that the differences are related to specific metabolic rates, as southern subspecies (acclimatized to the warmer environment) are more tolerant to increasing temperatures than the northern subspecies (acclimatized to the colder environment). The authors concluded that the two subspecies have unique plasticity and adaptation processes acting on the oxygen cascade. In accordance to that study and to Campos et al. (2016), this study found different mortality percentages between the two species, although the concept of phenotypic plasticity cannot be applied to explain the results, since different species were used. To better understand these differences, the anaerobic capacity of these two species was tested in the present work throughout the relative measurement of Ldh genes transcription and enzyme activities. Heuton et al. (2015) have shown that desert pupfish (Cyprinodon diabolis) that were acclimated differently to ecologically suitable temperatures exhibited periods of anaerobiosis when exposed to increasing temperatures, despite oxygen availability.

Acclimation and adaptation processes of organisms facing environmental oxygen or temperature changes involve two basic adjustments: (i) quantitative variations in genes expression by suppression or induction of control mechanisms, and (ii) qualitative changes affecting the production of alternative isoforms that favor adaptive changes (Hochachka and Somero, 2002). These quantitative changes reflect molecular mechanisms for the reorganization of metabolism that significantly contributes to the adaptive responses to abiotic environmental variations (Schulte, 2004). In the present study, the short- (two days) and long-term (30 days) exposure to future climate scenarios induced differential transcription of $l d h a-a$ and $l d h-b$ genes in $P$. axelrodi and $P$. simulans. We found that $P$. axelrodi survival was more affected than $P$. simulans when temperature was synergistically associated with carbon dioxide in the climate scenarios. We observed a significant increase in ldh-a mRNA transcription in P. axelrodi after two days (acute exposure) in mild emission scenario (Figure 2A), suggesting that this gene plays a significant role in the activation of anaerobic metabolism, providing rapid responses to temperature changes due to the sudden increase in fish energy demand (Almeida-Val et al., 2006). Seasonal variations of the $l d h-a$ and $l d h-b$ gene expression products were previously described in the tropical fish tambaqui (Colossoma macropomum) in their natural environment; variations were related to fluctuations of both temperature and dissolved oxygen (Almeida-Val et al., 1990). The increase of $l d h-a$ product in both heart and skeletal muscle of $C$. macropomum, along with the loss of $l d h-b$ product in heart tissue indicated the increase in anaerobic power during acclimatization. A similar trend occurred in the present study with $P$. axelrodi when considering the increase of ldh- $a$ transcripts.

The artificial acclimatization of both species for 30 days to increased temperature and $\mathrm{CO}_{2}$ levels caused adjustments of Ldh genes transcription. When exposed to the mild and moderate climate scenarios, specimens of $P$. axelrodi presented a decrease in the $l d h-a$ transcription and an accentuated increase in the $l d h-b$ transcription, respectively. Thus, this species does not rely entirely on anaerobic metabolism, requiring the contribution of $l d h-b$ gene, which is predominantly active in aerobic tissues (Figure 2A,B). Crawford and Powers (1992) observed an increase of $l d h-b$ mRNA in liver of killifish (Fundulus heteroclitus) acclimated to high temperatures. These changes result in increased survival (Powers and Schulte, 1998) and increased ability of tropical fishes in dealing with high temperatures in their natural environment (Edmunds et al., 2009). P. simulans, instead, increased Ldh gene transcripts after long-term experimental acclimatization (30 days) to the three scenarios (mild, moderate and extreme) (Figure 3A,B). Thus, $P$. simulans relies on anaerobic metabolism to survive higher metabolic demands. Wootton (1990) suggested that the biochemical and physiological responses depend on the time scale of the environmental changes. If the changes persist, fishes may acclimatize using adjustments in gene expression (phenotypic plasticity) to maintain its homeostasis (Almeida-Val et al., 1999). In this study, these changes in gene transcription reflected the Ldh activity levels.

Analysis of total Ldh activities (Table 3) revealed that after two days of exposure, head portions of both $P$. axelrodi and $P$. simulans had increased Ldh in moderate and extreme scenarios, suggesting an activation of anaerobic metabolism in tissues where Ldh- $\mathrm{B}_{4}$ isoform is predominant. According to Chippari-Gomes et al. (2005), the increase in Ldh levels with a concomitant decrease in citrate synthase (CS) in heart tissue of two Amazonian cichlids (Astronotus crassipinis and Symphysodon aequifasciatus) exposed to hypoxia and anoxia indicates the anaerobic potential of this tissue due to the accumulation of pyruvate and the concomitant decrease in aerobic metabolism. A similar trend occurred in tail portions (where $l d h$ - $a$ gene predominates) of the species herein analyzed, resulting in increased Ldh activities in the same moderate and extreme climate scenarios. Davies et al. (2011) observed changes in Ldh-A isoform activities in white muscle of the bluegill (Lepomis macrochirus) and the pumpkinseed (Lepomis gibbosus) after exposure to acute hypoxia. Pumpkinseed is a hypoxiatolerant species, which showed elevated activities of Ldh as well as higher transcript levels of $l d h-a$ mRNA compared to 
bluegill. The similarity of metabolic responses between animals exposed to hypoxia or high temperature reflect energy requirements of the cell due to lower oxygen availability in the cellular milieu. After 30 days, $P$. axelrodi and $P$. simulans reached a stabilized condition for Ldh in both body portions. Compared to the two-day exposure, a significant increase of anaerobic potential occurred in both parts of $P$. axelrodi acclimated to the current and mild scenarios, followed by a concomitant reduction in the moderate and extreme scenarios, suggesting a metabolic suppression in these conditions. Differently, for P. simulans, significant decreases in anaerobic metabolism in the head portion (moderate scenario) and tail portion (extreme scenario) were observed.

Acclimatization responses to environment challenges (in the present work, synergistic effects of elevated temperature and $\mathrm{CO}_{2}$ levels) often modulate the activities of metabolic enzymes (Crawford, 2002; Chippari-Gomes et al., 2005). Furthermore, Ldh activities can be altered by substrate concentration, temperature, oxygen, and $\mathrm{pH}$ (Almeida-Val et al., 1991). A recent review by Storey (2016) suggests that Ldh also changes its phosphorylation state as a stress-induced response in several organisms, including fishes. This post-translational modification (PTM) of Ldh leads to substantial changes in enzyme properties, so that the phosphorylated form is inhibited compared to the nonphosphorylated form. The changes of Ldh absolute activities in the two analyzed species suggest that post-translational changes, such as reversible protein phosphorylation or other epigenetic change, may explain the balance between anaerobic and aerobic metabolisms, helping fish to face different climate scenarios (Figure S2). Herein, Ldh measured with high pyruvate concentration $(10 \mathrm{mM}$, an inhibitory concentration for most fish tissues) presented increased values in head and tail portions of both species (Table S2), reflecting the absence of pyruvate inhibition in all experimental scenarios, i.e., increased anaerobic metabolism. These $\mathrm{L} / \mathrm{H}$ ratios confirm gene predominance for Ldh and indicate which type of metabolism (aerobic or anaerobic) is predominant in the tissues (Almeida-Val and Val, 1990). The two studied species displayed low or no inhibition ratios for Ldh at the two body parts (Figure 5). Either portion may contain higher amounts of skeletal muscle isoform, i.e., both portions must have more Ldh-A polypeptides than Ldh-B polypeptides, which can be seen in the ratios observed in Figure 4 regarding the overexpression of $l d h-a$ gene over $l d h-b$ in the whole body of these animals when exposed to all climate scenarios. In fact, $\mathrm{L} / \mathrm{H}$ ratios are lower in skeletal muscle as already described for many species (Almeida-Val and Val, 1990; Almeida-Val et al., 1991, 1995; Almeida-Val and Farias, 1996). Ldh-A A $_{4}$ orthologues are not inhibited by $10 \mathrm{mM}$ pyruvate, indicating the predominance of anaerobic metabolism in muscle tissues, which is expected especially in the tail portion of both species. As known, both species have a predominance of iso- zyme Ldh- $\mathrm{A}_{4}$ in the whole body, with a significant decrease of $\mathrm{Ldh}-\mathrm{B}_{4}$ isozyme in tail portion.

Long-term exposure to the extreme climate scenario may have induced an artificial acclimatization in both species, helping fish deal with environmental changes, although the species $P$. simulans can be considered better adapted than $P$. axelrodi. Also, $P$. simulans showed a higher ability to regulate Ldh gene transcription during short- and long-term exposure, which should help this species to better survive climate scenarios predicted for the year 2100 using its anaerobic power. In contrast, P. axelrodi was unable to regulate its $l d h-a$ and $l d h-b$ mRNA during such period, suggesting that the effects of climate change on tropical teleosts, particularly on fish of the Amazon, cannot be generalized.

Overall, Ldh gene regulation in these species leads to the predominance of anaerobic glycolysis in fish exposed to environmental climate change. We suggest that posttranslational modifications can also regulate protein kinetic properties to allow survival of these species; further studies are encouraged. In conclusion, these results reflect the particular adaptive characteristics that each species develops during the evolutionary line to cope with temperature changes in its own habitat, and how differently these congeneric species will be affected by the ongoing climate-driven environmental changes.

\section{Acknowledgments}

A joint grant from the Brazilian National Research Council (CNPq) and the Amazonas State Research Foundation (FAPEAM) to INCT-ADAPTA Project supported this work (grant numbers 573976/2008-2 and 3159/08, respectively). The authors are also grateful to Derek Campos, Elessandra Gomes, Fernanda Dragan and Jéssica de Souza for their assistance. Special thanks are to Nayara Castro, Priscila Nascimento and Ramon Baptista for their help with molecular biology protocols.

\section{References}

Almeida-Val VMF and Farias IP (1996) Respiration in fish of the Amazon: Metabolic adjustments to chronic hypoxia. In: Val AL, Almeida-Val VMF and Randall DJ (eds) Physiology and Biochemistry of the fishes of the Amazon. INPA, Manaus, pp 257-271.

Almeida-Val VMF and Hochachka P (1995) Air-breathing fishes: Metabolic biochemistry of the first diving vertebrates. In: Hochachka P and Mommsen T (eds) Biochemistry and Molecular Biology of Fishes. Environmental and Ecological Biochemistry, Amsterdam, pp 45-55.

Almeida-Val VMF and Val AL (1990) Adaptação bioquímica em peixes da Amazônia. Ciência Hoje 11:62-67.

Almeida-Val VMF and Val AL (1993) Evolutionary trends of LDH isozymes in fishes. Comp Biochem Physiol B 105:2128.

Almeida-Val VMF, Schwantes MLB and Val AL (1990) LDH isozymes in Amazon fish - I. Electrophoretic studies on two 
species from Serrasalmidae family: Mylossoma duriventris and Colossoma macropomum. Comp Biochem Physiol B 98:77-84

Almeida-Val VMF, Schwantes MLB and Val AL (1991) LDH isozymes in Amazon fish - II. Temperature and $\mathrm{pH}$ effects on LDH kinetic properties from Mylossoma duriventris and Colossoma macropomum (Serrasalmidae). Comp Biochem Physiol B 98:79-86.

Almeida-Val VMF, Val AL and Walker I (1999) Long- and short-term adaptation of Amazon fishes to varying $\mathrm{O}_{2}$-levels intraspecific phenotypic plasticity and interspecific variation. In: Val AL and Almeida-Val VMF (eds) Biology of Tropical Fishes. INPA, Manaus, pp 185-206.

Almeida-Val VMF, Chippari-Gomes AR and Lopes NP (2006) Metabolic and physiological adjustments to low oxygen and high temperature in fishes of the Amazon. In: Val AL, Almeida-Val VMF and Randall DJ (eds) The Physiology of Tropical Fishes. Elsevier, London, pp 443-500.

Almeida-Val VMF, Farias IP, Paula-Silva MN, Duncan WP and Val AL (1995) Biochemical adjustments to hypoxia by Amazon cichlids. Braz J Med Biol Res 28:1257-1263.

Ambrizzi T, Rocha RP, Marengo JA, Pisnitchenco I, Nunes LA and Fernandez JPR (2007) Cenários Regionalizados de Clima no Brasil e América do Sul Para o Século XXI: Projeções de Clima Futuro Usando Três Modelos Regionais. Ministério do Meio Ambiente, São Paulo, 108 p.

Anjos HDB, Amorim RMS, Siqueira JA and Anjos CR (2009) Exportação de peixes ornamentais do Estado do Amazonas, Bacia Amazônica, Brasil. Bras Inst Pesca 35:259-274.

Anjos NA, Schulze T, Brack W, Val AL, Schirmer K and Scholz S (2011) Identification and evaluation of cypla transcript expression in fish as molecular biomarker for petroleum contamination in tropical fresh water ecosystems. Aquat Toxicol 103:46-52.

Axelrod HR, Burgess WE, Pronek N and Walls JG (1986) Spawning the Neon Tetra, Paracheirodon innesi. In: Axelrod HR, Burgess WE, Pronek N and Walls JG (eds) Dr. Axelrod's Atlas of Freshwater Aquarium Fishes. T.F.H. Publications, New York, pp 194-197.

Bailey GS and Wilson AC (1968) Homologies between isoenzymes of fishes and those of higher vertebrates. Evidence for multiple $\mathrm{H}_{4}$ lactate dehydrogenases in trout. J Biol Chem 243:5843-5953.

Baptista RB, Souza-Castro N and Almeida-Val VMF (2016). Acute hypoxia up-regulates HIF-1 $\alpha$ and VEGF mRNA levels in Amazon hypoxia-tolerant Oscar (Astronotus ocellatus). Fish Physiol Biochem 42:1307-1318.

Beitinger TL, Bennett WA and McCauley RW (2000) Temperature tolerances of North American freshwater fishes exposed to dynamic changes in temperature. Environ Biol Fishes 58:237-275.

Boyd CE and Tucker CS (1992) Water Quality and Pond Soil Analyses for Aquaculture. Auburn University, Auburn, 183 p.

Beheregaray LB, Möller LM, Schwartz TS, Chao NL and Caccone A (2004) Microsatellite markers for the cardinal tetra Paracheirodon axelrodi, a commercially important fish from central Amazonia. Mol Ecol Resour 4:330-332.

Campos DF, Jesus TF, Kochhann D, Heinrichs-Caldas W, Coelho MM and Almeida-Val VMF (2016) Metabolic rate and thermal tolerance in two congeneric Amazon fishes: Parachei- rodon axelrodi Schultz, 1956 and Paracheirodon simulans, Géry 1963 (Characidae). Hydrobiologia 789:133-142.

Chippari-Gomes AR, Gomes LC, Lopes NP, Val AL and Almeida-Val VMF (2005). Metabolic adjustments in two Amazonian cichlids exposed to hypoxia and anoxia. Comp Biochem Physiol B 141:347-355.

Crawford DL (2002) Evolution of physiological adaptation. Cell Mol Resp Stress 3:297-314.

Crawford DL and Powers DA (1992) Evolutionary adaptation to different thermal environments via transcriptional regulation. Mol Biol Evol 95:806-813.

Davies R, Moyes CD and Wang YS (2011) Intra-and inter-specific variation in metabolic gene expression in relationship to environmental hypoxia. Comp Biochem Physiol A 159:25-31.

Driedzic WR and Almeida-Val VMF (1996) Enzymes of cardiac energy metabolism in Amazonian teleosts and the freshwater stingray (Potamotrygon hystrix). J Exp Zool 274:327-333.

Edmunds RC, van Herwerden L, Smith-Keune C and Jerry DR (2009) Comparative characterization of a temperature responsive gene (lactate dehydrogenase-B, ldh-b) in two congeneric tropical fish, Lates calcarifer and Lates niloticus. Int J Biol Sci 5:558-569.

Feely RA, Sabine CL, Lee K, Berelson W, Kleypas J, Fabry VJ and Millero FJ (2004) Impact anthropogenic $\mathrm{CO}_{2}$ on the $\mathrm{CaCO}_{3}$ system in the oceans. Science 305:362-366.

Guinotte JM and Fabry VJ (2008) Ocean acidification and its potential effects on marine ecosystems. Ann N Y Acad Sci 1134:320-342.

Heuton M, Ayala L, Burg C, Dayton K, McKenna K, Morante A, Puentedura G, Urbina N, Hillyard S, Steinberg S, et al. (2015) Paradoxical anaerobism in desert pupfish. J Exp Biol 218:3739-3745

Hochachka PW and Somero GN (1973) Temperature. In: Hochachka PW and Somero GN (eds) Strategies of Biochemical Adaptation. W.B. Saunders, Philadelphia, pp 203-215.

Hochachka PW and Somero GN (2002) Biochemical Adaptation: Mechanism and Process in Physiological Evolution. Oxford University Press, New York, 466 p.

Hochachka PW, Moon TW, Bailey J and Hulbert WC (1978) The osteoglossid kidney: Correlations of structure, function and metabolism with transition to air breathing. Can J Zool 56:820-832.

IPCC (2007) Summary for policymakers. In: Solomon S, Qin D, Manning M, Chen Z, Marquis M, Averyt KB, Tignor M and Miller HL (eds) Climate Change 2007: The Physical Science Basis. Contribution of Working Group I to the Fourth Assessment Report of the Intergovernmental Panel on Climate Change. Cambridge University Press, Cambridge, pp $1-17$.

Ishimatsu A, Kikkawa T, Masahiro H, Lee K and Kita J (2004) Effects of $\mathrm{CO}_{2}$ on marine fish: Larvae and adults. J Oceanogr 60:731-741.

Ishimatsu A, Hayashi M, Lee KS, Kikkawa T and Kita J (2005) Physiological effects on fishes in a high- $\mathrm{CO}_{2}$ world. $\mathrm{J}$ Geophys Res 110:C09S09.

Li W, Fu R and Dickinson RE (2006) Rainfall and its seasonality over the Amazon in the $21^{\text {st }}$ century as assessed by the coupled models for the IPCC AR4. J Geophys Res 111:D02111. 
Livak KJ and Schmittgen TD (2001) Analysis of relative gene expression data using real-time quantitative PCR and the $2^{-\Delta \Delta C t}$ method. Methods 25:402-408.

Marshall BG, Forsberg BR, Hess LL and Freitas CEC (2011) Water temperature differences in interfluvial palm swamp habitats of Paracheirodon axelrodi and $P$. simulans (Osteichthyes: Characidae) in the middle Rio Negro, Brazil. Ichthyol Explor Freshw 22:377-383.

McBryan TL, Healy TM, Haakons KL and Schulte PM (2016) Warm acclimation improves hypoxia tolerance in Fundulus heteroclitus. J Exp Biol 219:474-484.

Nobre AC, Sampaio G and Salazar L (2007) Mudanças climáticas e Amazônia. Cienc Cult 59:22-27.

Nobre AC, Sampaio G and Salazar L (2008) Cenários de Mudança Climática Para a América do Sul Para o Final do Século 21. Parcerias Estratégicas, Brasília, 24 p.

Oliveira AM and Val AL (2016) Effects of climate scenarios on the growth and physiology of the Amazonian fish tambaqui (Colossoma macropomum) (Characiformes: Serrasalmidae). Hydrobiologia 789:167-178.

Oliveira SR, Souza RTYB, Nunes ESS, Carvalho CSM, Menezes GC, Marcon JL, Roubach R, Akifumi OE and Affonso EG (2008) Tolerance to temperature, $\mathrm{pH}$, ammonia and nitrite in cardinal tetra, Paracheirodon axelrodi, an amazonian ornamental fish. Acta Amazon 38:773-780.

Powers DA and Schulte PM (1998) Evolutionary adaptations of gene structure and expression in natural populations in relation to a changing environment: A multidisciplinary approach to address the million-year saga of a small fish. J Exp Zool 282:71-94.

Prodocimo V and Freire CA (2001) Critical thermal maxima and minima of the platyfish Xiphophorus maculatus Günther (Poecillidae, Cyprinodontiformes) - a tropical species of ornamental freshwater fish. Rev Bras Zool 18:97-106.
Salazar LF, Nobre CA and Oyama MD (2007) Climate change consequences on the biome distribution in tropical South America. Geophys Res Lett 34:1-6.

Schmidt-Nielsen K (2002) Effects of temperature. In: SchmidtNielsen K (ed) Animal Physiology: Adaptation and Environment. Santos Press, São Paulo, pp 217-240.

Schulte PM (2004) Changes in gene expression as biochemical adaptation to environmental change: a tribute a Peter Hochachka. Comp Biochem Physiol B 139:519-529.

Storey KB (2016) Comparative enzymology - New insights from studies of an "old" enzyme, lactate dehydrogenase. Comp Biochem Physiol B 199:13-20.

Whitt GS, Miller ET and Shaklee JB (1973) Developmental and biochemical genetics of lactate dehydrogenase isozymes in fishes. In: Schroeder JH (ed) Genetics and Mutagenesis of Fish. Springer, Berlin, pp 243-276.

Wootton RJ (1990) Bioenergetics. In: Wootton RJ (ed) Ecology of Teleost Fishes. Chapman and Hall, London, pp 73-95.

\section{Supplementary material}

The following online material is available for this article: Figure S1 - Environmental conditions of the microcosms in 30 days of experiment.

Figure S2 - Pearson's correlations for Ldh relative gene expression and enzyme activity.

Table S1 - Partial sequences of the $l d h-a, l d h-b$ and $18 S$ genes.

Table S2 - Lactate dehydrogenase (Ldh) activity in head and tail portions.

Associate Editor: Klaus Hartfelder

License information: This is an open-access article distributed under the terms of the Creative Commons Attribution License (type CC-BY), which permits unrestricted use, distribution and reproduction in any medium, provided the original article is properly cited. 